\begin{tabular}{|c|l|}
\hline Title & Oceanic Rossby waves induced by the meridional shift of the ITCZ in association with ENSO events \\
\hline Author(s) & A be, Hiroto; Tanimoto, Y ouichi; Hasegawa, Takuya; Ebuchi, Naoto; Hanawa, Kimio \\
\hline Citation & $\begin{array}{l}\text { Journal of Oceanography, 70(2), 165-174 } \\
\text { https://doi.org/10.1007/310872-014-0220-1 }\end{array}$ \\
\hline Issue Date & 201404 \\
\hline Doc URL & http://hdl.handle.net/2115/58423 \\
\hline Rights & The final publication is available at link.springer.com \\
\hline Type & article (author version) \\
\hline File Information & Jo070-2 165-174.pdf \\
\hline
\end{tabular}

Instructions for use 


\title{
Oceanic Rossby waves induced by the meridional shift of the ITCZ in association with ENSO events
}

\author{
Hiroto $\mathrm{Abe}^{1}$, Youichi Tanimoto ${ }^{2,3}$, Takuya Hasegawa ${ }^{3,4}$, Naoto Ebuchi ${ }^{1}$ and Kimio \\ Hanawa $^{5}$
}

1. Institute of Low Temperature Science, Hokkaido University, Kita-19, Nishi-8, Kita-ku, Sapporo 060-0819, Japan

2. Faculty of Environmental Earth Science, Hokkaido University, Kita-10, Nishi-5, Kita-ku, Sapporo 060-0810, Japan

3. Research Institute for Global Change, Japan Agency for Marine-Earth Science and Technology, Yokosuka 237-0061, Japan

4. Earth Simulator Center, Japan Agency for Marne-Earth Science and Technology, Yokohama 236-0001, Japan

5. Department of Geophysics, Graduate School of Science, Tohoku University, 6-3, Aramaki-Aza-Aoba, Aoba-ku, Sendai 980-8578, Japan

Email: abe@lowtem.hokudai.ac.jp

Jan 21, 2014 


\begin{abstract}
This study investigated the eastern Pacific Intertropical Convergence Zone (ITCZ) as an atmospheric forcing to the ocean by using various observed and reanalysis data sets over 29 years. Climatologically, a zonal band of positive wind stress curl (WSC) with a $10^{\circ}$ meridional width was exhibited along the ITCZ. A southward shift of the positive WSC band during the El Niño phase induced a negative (positive) WSC anomaly along the northern (southern) portion of the ITCZ, and vice versa during the La Niña phase. This meridional dipole accounted for more than $25 \%$ of interannual variances of the WSC anomalies (WSCAs), based on analysis of the period 1993-2008. The negative (positive) WSCA in the northern portion of the ITCZ during the El Niño (La Niña) phase was collocated with a positive (negative) sea surface height anomaly (SSHA) that propagated westward as a Rossby wave all the way to the western North Pacific. This finding indicates that this off-equatorial Rossby wave is induced by the WSCA around the ITCZ. Our analysis of a 1.5-layer reduced gravity model revealed that the Rossby waves are mostly explained by wind stress forcing rather than reflection of an equatorial Kelvin wave on the eastern coastal boundary. The off-equatorial Rossby wave had the same SSHA polarity as the equatorial Kelvin wave, and generation of a phase-preserving Rossby wave without the Kelvin wave reflection was explained by meridional movement of the ITCZ. Thus, the ITCZ acts as an atmospheric bridge that connects the equatorial and off-equatorial oceanic waves.
\end{abstract}




\section{Introduction}

The Intertropical Convergence Zone (ITCZ) is a region characterized by the presence of convective clouds and large amounts of precipitation where surface winds converge. While the eastern Pacific ITCZ is located between $5^{\circ} \mathrm{N}$ and $15^{\circ} \mathrm{N}$ on average, its location and intensity are strongly affected by underlying seasonal and interannual variations of sea surface temperature (SST) (Horel 1982; Pazan and Meyers 1982). A large SST variation in the eastern equatorial Pacific region associated with El Niño (La Niña) leads to a southward (northward) shift of the eastern Pacific ITCZ (Pazan and Meyers 1982; Philander 1989) and changes in surface wind patterns that can act as the atmospheric forcing anomalies to the ocean surface layers.

Anomalous Ekman pumping induced by wind stress curl (WSC) anomalies can generate sea surface height (SSH) anomalies that propagate westward as a Rossby wave in the off-equatorial region. In the eastern Pacific region where the ITCZ is located, two types of Rossby waves emerge in a cycle of the El Niño Southern Oscillation (ENSO). Kessler (1990) and Hasegawa and Hanawa (2003) reported a Rossby wave along the northern portion of the ITCZ $\left(9-15^{\circ} \mathrm{N}\right)$ in the eastern Pacific on the basis of analyses of observed hydrographic data sets. Their analyses indicated that the Rossby wave begins to propagate westward from the eastern coastal boundary right after the equatorial Kelvin wave reaches the eastern coastal boundary. This finding implies that the Rossby waves are generated by reflection of the equatorial Kelvin wave. On the other hand, Schopf and Suarez (1988) demonstrated a Rossby wave along the southern portion of the ITCZ $\left(5-7^{\circ} \mathrm{N}\right)$ in the central Pacific on the basis of numerical experiments. Their experiments indicated that the Rossby wave is generated by anomalous atmospheric forcing as a response to SST variation associated with the Kelvin wave propagation 
along the equator. This Rossby wave revealed by the numerical experiments has not been clearly captured by the observational studies.

These two off-equatorial Rossby waves, reported in the previous literature, are triggered by the equatorial Kelvin wave arrived in the eastern Pacific. At the same time, the Kelvin wave also leads to meridional migration of the ITCZ as a response to El Niño and La Niña events. While this meridional shift of the ITCZ is expected to change the surface wind patterns, no literature has discussed how the meridional migration of the ITCZ is related to the two Rossby waves via changes in surface wind patterns. Investigation of the ITCZ focusing on its impact on oceanic height variability may lead to a deeper understanding of air-sea interactions in the eastern Pacific in an ENSO cycle.

Therefore, the objective of this study is to examine wind stress fields associated with northward/southward shifts of the ITCZ and their relation to Rossby wave generation. The paper is organized as follows. Section 2 describes the data used and analysis methods. Section 3 examines the climatological field and temporal variations of the meridional position of the ITCZ. Section 4 depicts anomalous wind stress fields associated with the northward/southward shifts of the ITCZ and examines their relation to generation of the Rossby waves along the two meridional sides of the ITCZ. Section 5 discusses the generation mechanism of the Rossby waves using a simple dynamic model. A summary is presented in Section 6.

\section{Data and methods}

A globally merged product of satellite-derived infrared (IR) brightness temperature provided by the National Climatic Data Center (NCDC) in the National Oceanic and 
Atmospheric Administration (NOAA) (Gridsat, Knapp et al. 2011) was used. The merged product was derived from the historical data records of the International Satellite Cloud Climatology Project (ISCCP). The IR data is based on satellite measurements in an infrared window $(11 \mu \mathrm{m})$ that senses the Earth's surface under clear-sky conditions and cloud-top temperatures of thick clouds. While the original data is available at 3 -hour intervals and $0.07^{\circ}$ longitude $\times 0.07^{\circ}$ latitude, we used spatially smoothed monthly averages. For the smoothing, we applied a Gaussian filter with an e-folding scale of $300 \mathrm{~km}$.

SST data provided by the Met Office Hadley Centre (HadISST, Rayner et al. 2003) was used. The HadISST data is constructed based on quality-controlled in situ temperature observations, available at 1 -month intervals and $1^{\circ}$ longitude $\times 1^{\circ}$ latitude Spatial and temporal gaps are filled in using a reduced space optimal interpolation (Kaplan et al. 1997).

Surface wind stress data provided by the European Center for Medium-Range Weather Forecasts (ECMWF), named Interim ECMWF RE-Analysis (ERA-Interim, Simmons et al. 2010), was used. The number of assimilated observations is 10 times larger in the ERA-Interim than in the previous version of the 40-year ECMWF Re-Analysis (ERA-40) (Dee et al. 2011). Although the original data is available at 1-month intervals and $1.5^{\circ}$ longitude $\times 1.5^{\circ}$ latitude, we re-gridded the data into a $1^{\circ}$ grid by linear interpolation.

We calculated monthly climatologies over a 29-year period of 1980-2008 for each of the variables. Monthly anomalies as departures from the respective climatologies were smoothed by applying a 13-month running mean filter. This temporal filter highlights interannual variations of those variables by canceling out temporal variations 
on a 1-year scale.

SSH anomalies (SSHAs) observed by satellite altimeters including TOPEX/Poseidon and Jason-1 are provided by the Archiving, Validation and Interpretation of Satellite Oceanographic Data (AVISO) from January 1993 to December 2008. While the original anomaly data along their ground tracks is available at 9.916-day and $5.8 \mathrm{~km}$ intervals, we calculated the monthly averages smoothed by the same spatial filter used for the IR data. To remove the seasonal bias, we re-defined the monthly SSHAs as departures from the 16-year mean in the respective month. Then, annual mean SSHAs were calculated based on the 13-month running mean of the re-defined monthly anomalies.

An annual mean $1^{\circ} \times 1^{\circ}$ gridded absolute SSH data set was constructed using the annual mean density profile based on the annual mean temperature and salinity profiles archived in the NOAA National Oceanographic Data Center (NODC). Absolute SSH on each of the grid point was calculated by integrating the density profiles referenced to 2000 dbar under an assumption of hydrostatic equilibrium.

\section{ITCZ and wind stress curl}

To obtain an outlook of the ocean-atmosphere field around the eastern Pacific ITCZ, we show annual mean IR, SST, and surface wind stress fields in Fig. 1. The ITCZ is characterized by lower IR temperature than in the surrounding areas (Bain et al. 2010). The zonal band of the IR temperature below $278 \mathrm{~K}$ elongates in the off-equatorial region north of the equator, tilting slightly from $2-8^{\circ} \mathrm{N}$ in the western portion to $6-13^{\circ} \mathrm{N}$ in the eastern portion. The ITCZ is collocated with the high SST region over $27^{\circ} \mathrm{C}$ and with convergence of the surface trade winds (Fig. 1a). Because the westward component 
in the wind stress vectors are stronger to the north of the ITCZ than south, a zonal band of positive wind stress curls (WSCs) with approximately $10^{\circ}$ meridional width is found in a region slightly north of the ITCZ (Fig. 1b). The magnitude of the positive WSC in this band reaches up to $8 \times 10^{-8} \mathrm{~N} \mathrm{~m}^{-3}$, which is comparable to that of the negative WSCs over the North Pacific subtropical gyre (Trenberth et al. 1990). Due to the wind-induced upwelling, the SSH displays an off-equatorial trough along $8-13^{\circ} \mathrm{N}$ under a zonal band of the positive WSC, which is separated from the equatorial trough centered at the equator induced by the equatorial upwelling (Fig. 1c). This observed picture of climatological WSC and SSH in the eastern Pacific are fairly in agreement with the surface wind vorticity (Horel 1982) and the meridional change of thermocline depth found in Levitus (1982)'s temperature cross section of the subsurface ocean (e.g., Xie and Philander 1994).

The zonal band of the ITCZ migrates meridionally with seasonal cycles (being southernmost during the boreal spring, Horel 1982) as well as on interannual time scales (Pazan and Meyers 1982). To obtain the meridional position of the ITCZ band, we defined a representative latitude of the ITCZ, $Y_{I T C Z}(t)$, following Waliser and Gautier (1993),

$$
Y_{I T C Z}(t)=\frac{\iint_{\text {box }_{I T C Z}} a(x, y, t) y d x d y}{\iint_{\text {box }_{\text {ITCZ }}} a(x, y, t) d x d y},
$$

where $a$ is the IR temperature, which is a function of longitude $(x)$, latitude $(y)$, and time $(t)$. Spatial integration was conducted in a domain of $180-110^{\circ} \mathrm{W}$ and $0-18^{\circ} \mathrm{N}$ (box ITCZ, inset rectangle in Fig. 1) only when the IR temperature is below $278 \mathrm{~K}$. Although the box was chosen following Bain et al. (2011), the threshold in IR temperature for the 
monthly averaged data is much higher than those in the range of $230-250 \mathrm{~K}$ used by previous studies to examine ITCZ variability based on hourly scale data (see Table 1 of Bain et al. (2010)). We also defined a representative latitude of the positive WSC band, $Y_{W S C}(t)$. Spatial integration of WSC over box ${ }_{I T C Z}$, instead of IR temperature, was conducted only when the WSC was positive. Monthly anomalies, $Y_{I T C Z}^{\prime}(t)$ and $Y^{\prime}{ }_{W S C}(t)$, calculated as departures from the monthly climatologies of $Y_{I T C Z}(t)$ and $Y_{W S C}(t)$ respectively, were smoothed by a 13-month running mean.

As stated in the introduction, $Y_{I T C Z}^{\prime}(t)$ is negatively correlated with the Niño 3.4 index (correlation coefficient $\mathrm{r}=-0.81$, Fig. 2). While the amplitudes are smaller in $Y^{\prime}{ }_{W S C}(t)$ than in $Y^{\prime}{ }_{I T C Z}(t)$, these two indices are highly correlated $(\mathrm{r}=+0.62)$. Consequently, the correlation between $Y^{\prime}{ }_{W S C}(t)$ and the Niño 3.4 index is also negative $(\mathrm{r}=-0.47)$, showing that the positive WSC band shifts southward (northward) by a few degrees in latitude during El Niño (La Niña) years.

For simplicity, we hereafter employ only $Y^{\prime}{ }_{I T C Z}(t)$, instead of $Y^{\prime}{ }_{W S C}(t)$, for statistical analyses in the present study because of the significant correlation of the two indices. The results in the later sections are mostly identical when we employ $Y^{\prime}{ }_{W S C}(t)$.

\section{Baroclinic Rossby waves and north/south shift of the ITCZ}

To identify the spatial patterns of SST, WSC, and SSH anomalies when the ITCZ migrates southward, we made regression maps of those variables onto reversed $Y_{\text {ITCZ }}^{\prime}(t)$, i.e., $-Y_{\text {ITCZ }}^{\prime}($ ) (Fig. 3). Positive SST anomalies (SSTAs) are pronounced in the equatorial region (Fig. 3a). In the WSC anomaly (WSCA) field (Fig. 3b), a zonal band of negative (positive) anomalies is found in the area of $9-18^{\circ} \mathrm{N}\left(0-9^{\circ} \mathrm{N}\right)$ north (south) of the climatological ITCZ at $165-110^{\circ} \mathrm{W}\left(180-110^{\circ} \mathrm{W}\right)$, forming a zonally-elongated 
meridional dipole, as the positive WSC band shown in Fig. 1b migrates southward. Amplitudes of the regressed WSCA at $9-18^{\circ} \mathrm{N}\left(0-9^{\circ} \mathrm{N}\right)$ is more than $0.5 \times 10^{-8} \mathrm{~N} \mathrm{~m}^{-3}$ $\operatorname{deg}^{-1}\left(1.0 \times 10^{-8} \mathrm{~N} \mathrm{~m}^{-3} \mathrm{deg}^{-1}\right)$ at the center of action, which accounts for more than $25 \%$ of the interannual variance of the WSCAs. Qiu and Chen (2010) showed a similar meridional dipole of the regressed WSCA onto the Niño 3.4 index (see Fig. 11b of their paper), instead of $Y^{\prime}{ }_{I T C Z}(t)$. Although they discussed neither the dipole pattern nor its relationship with the ITCZ location, the similarity of the two WSCA patterns is reasonable because of the significant correlation between $Y_{\text {ITCZ }}^{\prime}(t)$ and the Niño3.4 index.

In the regressed SSHA field in Fig. 3c, two tongue-like structures of positive SSHAs extending westward from the eastern coastal boundary are found over the equatorial and off-equatorial $\left(9-15^{\circ} \mathrm{N}\right)$ regions, sandwiching the meridional minimum of SSHA at $5-7^{\circ} \mathrm{N}$. This equatorial SSHA ridge is collocated with a positive SSTA along the equator (Fig. 3a). However, such a linkage to the SSTA is not found in the off-equatorial SSHA ridge and trough. Instead, this off-equatorial SSHA ridge along 9$15^{\circ} \mathrm{N}$ (SSHA trough along $5-7^{\circ} \mathrm{N}$ ) is collocated with a negative (positive) WSCA (Fig. 3b), indicating that the ridge (trough) is generated by anomalous Ekman downwelling (upwelling) induced by surface wind changes associated with the southward shift of the ITCZ.

In order to capture the temporal evolution of the SSHA field, we mapped the monthly lead-lag regression of the SSHA onto $-Y^{\prime}{ }_{I T C Z}(t)$ over the entire tropical North Pacific (Fig. 4). The monthly lead-lag value is negative (positive) when the SSHA leads (lags) $\left(-Y^{\prime}{ }_{I T C Z}(t)\right)$. The two SSHA ridges found in the eastern Pacific at lag $=0$ month (Figs. 4c and 3c) show different propagation features as expected from the ocean wave 
dynamics. The equatorial ridge is a consequence of eastward propagation of a warm Kelvin wave (Figs. $4 \mathrm{a}-\mathrm{c}$ ). The arrival of the Kelvin wave at the eastern coastal boundary corresponds to a southward shift of the ITCZ in association with the mature phase of El Niño. The off-equatorial SSHA ridge begins to be formed in the eastern Pacific at lag $=0$ month and shows a Rossby wave feature along $9-15^{\circ} \mathrm{N}$ (the northern portion of the ITCZ). After ridge formation, the off-equatorial positive SSHA propagates westward (Fig. 4d), and eventually arrives at the western coastal boundary of the Pacific at lag $=+12$ months (Fig. 4e). These properties of the Rossby wave are fairly in agreement with the result of the observational studies by Kessler (1990) and Hasegawa and Hanawa (2003). On the other hand, along $5-7^{\circ} \mathrm{N}$ (the southern portion of the ITCZ), the off-equatorial SSHA trough sandwiched by the two ridges is also formed in the central Pacific at lag $=0$ month, at the same time as the ridge formation to the north (Fig. 4c). However, the Rossby wave feature is not discernible at $5-7^{\circ} \mathrm{N}$, probably because the signal of the SSHA trough is overwhelmed by the subsequent cold Kelvin wave propagating from the western Pacific. This result is inconsistent with the result of the numerical simulation by Schopf and Suarez (1988). Thus our analysis of the observations, along with the above-mentioned observational studies, indicates that the SSHA trough formed along the southern portion of the ITCZ does not show any clear propagation feature as a Rossby wave. For this reason, only the Rossby wave at $9-15^{\circ} \mathrm{N}$ is the focus of further analysis.

To see the behaviors of individual ocean waves, we made Hovmöller diagrams of SSHAs (Fig. 5) along the equator $\left(3^{\circ} \mathrm{S}-3^{\circ} \mathrm{N}\right)$ and the off-equatorial latitudinal belt (9$15^{\circ} \mathrm{N}$ ), as shown by inset rectangles in Fig. 4. Note that the longitudinal direction in Fig. $5 \mathrm{~b}$ is opposite to that in Fig. 5a. To estimate a propagation speed, the SSHAs were 
projected onto a line at a range of angles from $0^{\circ}$ (the longitude axis) to $90^{\circ}$ (the time axis) in the Hovmöller diagram (Fig. 5a). When the line is perpendicular to the alignment of ridges and troughs of the Rossby waves, the projection has a minimum variance of SSHAs. Based on this method, we estimated the propagation speed at $20 \mathrm{~cm}$ $\mathrm{s}^{-1}$. While the westward propagations of the Rossby waves are pronounced in the off-equatorial belt (Fig. 5a), their starting longitudes are different from year to year. Before 2002, the SSHAs in the off-equatorial belt can be traced back to the eastern coastal boundary and then all the way to the equatorial region. This counter-clockwise propagation indicates a reflection of the ocean waves at the eastern coastal boundary, as reported by the above-mentioned observational studies. In contrast, during 2002-2008, such a linkage of the SSHA between the equatorial and off-equatorial regions is weak. El Niño Modoki (Ashok et al. 2007) and/or its similar events (Larkin and Harrison 2005; Kao and Yu 2009; Kug et al. 2009) have been frequently observed since 2002, while those events were less found before 2002 (Singh et al. 2011; Hasegawa et al. 2013). These changes in the zonal location of the equatorial SST warming are associated with an interdecadal change in the propagation feature of the Kelvin waves. Though the Kelvin wave reflection is not discernible in this period, the SSHA polarity between the two latitudes is linked by some physical mechanism. As mentioned in Fig. 3, the WSCA dipole associated with the meridional migration of the ITCZ has potential to generate the Rossby waves including the linkage of the SSHA polarity. In fact, $Y^{\prime}{ }_{I T C Z}(t)$ is correlated to both the SSHA (Fig. 5a) and WSCA in this off-equatorial belt (r $=+0.43$, Fig. 5c). In the next section, the off-equatorial Rossby wave is further examined in view of wind stress forcing with special emphasis on the WSCA dipole associated with meridional migration of the ITCZ. 


\section{Generation mechanism of off-equatorial Rossby waves}

To simulate wind-driven Rossby waves, a reduced gravity model (1.5-layer) was employed. This model has successfully reproduced the wave features in many studies (e.g. Meyers 1979; Kessler 1990; Fu and Qiu 2002; Capotondi et al. 2003; Qiu and Chen 2010). Under the long-wave approximation, a linear vorticity equation is obtained as follows:

$$
\frac{\partial h}{\partial t}-C_{R} \frac{\partial h}{\partial x}=-\frac{g^{\prime}}{\rho_{0} g} \nabla \times\left(\frac{t}{f}\right)-\varepsilon h
$$

where $h$ is the SSHA, $t$ is the wind stress anomaly, $C_{R}$ is the propagation speed of the long baroclinic Rossby waves, $g^{\prime}$ is the reduced gravity, $\rho_{0}$ is the reference density, $f$ is the Coriolis parameter, and $\varepsilon$ is the dissipation ratio. For a simple discussion, we assumed that the beta effect in the local Ekman pumping term was negligible as expressed by the following equation,

$$
\frac{\partial h}{\partial t}-C_{R} \frac{\partial h}{\partial x}=-\frac{g^{\prime}}{\rho_{0} g f} \nabla \times t-\varepsilon h .
$$

Note that we checked that the beta effect is unlikely to influence the following results in this section. Indeed, Qiu and Chen (2010) also removed the beta effect on the simulation of the off-equatorial Rossby waves. By integrating this equation from the eastern boundary $\left(x_{E}\right)$ along the baroclinic Rossby wave characteristics, then we obtain,

$$
\begin{aligned}
& h(x, y, t)=h\left(x_{E}, y, t+\frac{x-x_{E}}{C_{R}}\right) \exp \left(\varepsilon\left(x-x_{E}\right) / C_{R}\right)+ \\
& \frac{g^{\prime}}{\rho_{0} g f C_{R}} \int_{x_{E}}^{x} k \cdot \nabla \times t\left(x^{\prime}, y, t+\frac{x-x^{\prime}}{C_{R}}\right) \exp \left(\varepsilon\left(x-x^{\prime}\right) / C_{R}\right) d x^{\prime} .
\end{aligned}
$$

The first term on the right-hand side represents Rossby waves emitted from the eastern 
coastal boundary. This implicitly indicates reflection of the equatorial Kelvin wave on the eastern boundary. The SSHA observed at $100^{\circ} \mathrm{W}$ was used as the boundary condition. The second term on the right-hand side is a component forced by WSCAs. We determined the value of $C_{R}$ by the same method used for Fig. 5a. Based on individual longitude-time diagrams of the observed SSHA at each of latitude from $9^{\circ}$ to $15^{\circ} \mathrm{N}$, the estimated speed was $25-15 \mathrm{~cm} \mathrm{~s}^{-1}$. The WSCA was zonally integrated following Eq. 4 under the condition that $g^{\prime}$ was $0.04 \mathrm{~m} \mathrm{~s}^{-2}, \varepsilon$ was $(6 \text { months })^{-1}$ (Picaut et al. 1993; Qiu and Chen 2010), and $x_{E}$ was $100^{\circ} \mathrm{W}$.

Figure 6a displays simulated SSHAs along the off-equatorial belt calculated by the sum of the following two terms: 1) the Rossby waves emitted from the eastern coastal boundary shown in Fig. $6 \mathrm{~b}$ and 2) the wind-induced Rossby waves shown in Fig. 6c. While the SSHA produced by the first term (Fig. 6b) reduces during westward propagation by the given dissipation ratio, the SSHA produced by the second term (Fig. 6c) dominates in the central and western parts of the simulated SSHAs in Fig. 6a. Our visual inspection indicates that the simulated SSHAs (Fig. 6a) successfully reproduce the overall features of the observed SSHAs (Fig. 5a). In fact, the observed (Fig. 5a) and simulated SSHAs (Fig. 6a) as a function of time are significantly correlated at all longitudes from $180^{\circ}$ to $100^{\circ} \mathrm{W}$ (thin line of Fig. 6e).

The significant correlation coefficients over 0.8 in the eastern and western portions of the analysis region are attributed to different factors. In the eastern portion, most of the SSHA patterns in Fig. 6a are determined by the first term (Fig. 6b) rather than the second term (Fig. 6c). However, the correlation coefficients between the first term (Fig. 6b) and the observed SSHA (Fig. 5a) show a rapid westward decrease (dashed line in Fig. 6e). By contrast, the correlation coefficients between the second term (Fig. 6c) and 
the observed SSHA (Fig. 5a) show a gradual westward increase (thick line in Fig. 6e). This indicates that wind stress forcing is very important for the generation of the Rossby wave in the interior region far from the eastern boundary. The switching of the relative importance from the emission term to the wind stress term is found at $120-130^{\circ} \mathrm{W}$ where the meridional dipole of the WSCA is dominant (Fig. 3). We note that the overall features of the simulated results were unchanged when we employed the dissipation ratio smaller than $(3 \text { months })^{-1}$.

Visual comparison of Figs. $6 \mathrm{c}$ and $6 \mathrm{~d}$ indicates that on an interannual time scale, the wind-driven off-equatorial Rossby wave has the same SSHA polarity as the observed equatorial Kelvin wave in the same year. The time-longitude section of the lag correlation coefficients between the observed equatorial SSHA and the observed SSHA at $0^{\circ} \mathrm{N}$ and $180^{\circ} \mathrm{W}$ displays an eastward decrease as the Kelvin wave propagates (Fig. $6 \mathrm{~g})$. In contrast, the time-longitude section of the lag correlation coefficients for the wind-driven off-equatorial Rossby wave shows a westward increase as the lag-time increases (Fig. 6f). The significant positive correlation coefficients west of $120-130^{\circ} \mathrm{W}$ imply a linkage of the polarity between the equatorial and off-equatorial SSHA. This finding indicates that the wind forcing is one possible physical factor that can preserve the same polarity of equatorial and off-equatorial ocean waves, since the reflection effect is not involved in the off-equatorial waves shown in Fig. 6c.

During the pre-mature phase of El Niño events, the arrival of the downwelling warm Kelvin wave in the eastern Pacific induces a positive SSHA, as in Fig. 5b. An SST warming after the Kelvin wave arrival leads to southward movement of the eastern Pacific ITCZ accompanying the negative WSCA along the northern portion. This atmospheric response then generates the positive SSHA that propagates westward as an 
off-equatorial Rossby wave. Thus, the meridional movement of the ITCZ plays a role as a bridge connecting the equatorial and off-equatorial ocean waves. The same relation is true for SSHAs during La Niña events with opposite polarity.

We should note that the WSCAs for the forcing in Eq. 4 contain the ITCZ-related variability as well as other natural fluctuations. Therefore, we conducted another experiment forced by the ITCZ-related WSCAs ( $\left.W S C A_{\text {ITCZ }}\right)$ calculated as follows:

$$
\operatorname{WSCA}_{I T C Z}(x, y, t)=W S C A_{\text {reg }}(x, y) \times Y_{I T C Z}^{\prime}(t) \text {. }
$$

$W S C A_{\text {reg }}$ represents a regression of the WSCA onto $Y^{\prime}{ }_{I T C Z}(t)$ as shown in Fig. $3 \mathrm{~b}$. All other settings are identical to the experiment in Fig. 6c. The result of the additional experiment shows that the overall features are similar to those in Fig. 6c (not shown). The SSHA in the additional experiment explains $22 \%$ of the interannual variance of the observed SSHA. This reduction in the explained variance is consistent with the result of our observational analysis in Section 4; that is, the regressed WSCAs onto $Y_{I T C Z}^{\prime}(t)$ in the off-equatorial belt explained $25 \%$ of the total interannual variance.

Due to the fact that $Y^{\prime}{ }_{I T C Z}(t)$ is highly correlated with the Niño 3.4 index (Fig. 2, r $=$ -0.81), the $W S C A_{\text {reg }}$ in Eq. 5 may contain a component of the effect of the ITCZ shift together with a component that directly responds to the equatorial SST warming. However, WSC and surface wind divergence anomalies averaged over the region at 9$15^{\circ} \mathrm{N}$ and $165-120^{\circ} \mathrm{W}$ were temporally correlated $(\mathrm{r}=-0.66)$. Therefore, it is considered that the term in Eq. 5 contains much of the component derived from the ITCZ shift.

\section{Summary}

We examined anomalous atmospheric forcing associated with northward/southward 
movements of the eastern Pacific ITCZ and the oceanic response to these atmospheric forcing anomalies by using various observed and reanalysis data sets over 29 years. Climatologically, a zonal band of positive WSC with a meridional width of approximately $10^{\circ}$ was exhibited along the eastern Pacific ITCZ. Southward migration of the ITCZ during El Niño years induced a meridional dipole of WSCAs with a negative zonal band of WSCA along the northern portion of the ITCZ at $9-18^{\circ} \mathrm{N}$ and a positive one along the southern portion at $0-9^{\circ} \mathrm{N}$. The meridional WSCA dipole accounted for more than $25 \%$ of the total interannual variation of the WSCAs, based on analysis of the period $1993-2008$. The negative WSCA at $9-18^{\circ} \mathrm{N}$ was collocated with a positive SSHA at $9-15^{\circ} \mathrm{N}$ when the ITCZ migrates southward during El Niño years. At the same time, the equatorial SSHA was positive because of the arrival of a warm Kelvin wave. The opposite relation in the polarity of the SSHA in each latitudinal band is true during La Niña years. The SSHAs along a northern portion of the ITCZ were generated by the WSCA associated with meridional movement of the ITCZ.

After the off-equatorial SSHA dipole was generated, the observed SSHA at 9-15ㅇ propagates as an off-equatorial Rossby wave. Consequently, the equatorial Kelvin wave and off-equatorial Rossby wave were represented by the same sign in SSHAs. The observed Rossby wave feature in the SSHA was successfully reproduced in a 1.5-layer reduced gravity model. This finding indicates that the off-equatorial Rossby waves were mostly generated by wind stress forcing rather than by ocean wave reflection on the eastern coastal boundary. However, the wind stress forcing itself could not explain why the off-equatorial Rossby wave had the same SSHA polarity as the equatorial Kelvin wave on an interannual time scale.

This study proposes that the meridional migration of the ITCZ is necessary for the 
phase-preserving ocean waves between the equatorial and off-equatorial regions without any wave reflection at the eastern boundary. 1) The arrival of the warm Kelvin wave in the eastern Pacific induces a positive SSHA in the equatorial region. 2) Then, SST warming leads the southward movement of the ITCZ, which accompanies the negative WSCA along its northern portion. 3) This atmospheric response finally generates a positive SSHA that propagates westward as a Rossby wave. Thus, the ITCZ acts as an atmospheric bridge connecting equatorial and off-equatorial oceanic waves.

As shown in Figs. 4c-e, the off-equatorial Rossby wave propagates from the eastern Pacific all the way to the western boundary, which is consistent with Kessler (1990) and Hasegawa and Hanawa (2003). After the arrival at the western boundary, this Rossby wave will reflect (Boulanger and $\mathrm{Fu}$ 1996) and/or generate an oceanic Kelvin wave through atmospheric forcing (Weisberg and Wang 1997), leading to a subsequent ENSO event. Thus, the off-equatorial Rossby wave associated with meridional movement of the ITCZ can be a part of the possible oscillator of ENSO. However, recent studies have pointed out zonal modulation of El Niño events (Larkin and Harrison 2005; Ashok et al. 2007; Kao and Yu 2009; Kug et al. 2009). Therefore, we should further investigate this possible oscillator by considering the zonal modulation in the equatorial SST warming. 


\section{Acknowledgments}

We would like to thank the editor (Dr. Tomoki Tozuka) and two anonymous reviewers who provided fruitful comments to improve the manuscript. The satellite altimeter data was provided by the AVISO; the wind stress data by the ECMWF; the IR data, the climatological T/S profiles and the Niño 3.4 index by the NOAA; and the SST data by the Met Office Hadley Centre. We would like to thank all the data providers. 


\section{References}

Ashok, K., S. K. Behera, S. A. Rao, H. Weng, and T. Yamagata, 2007: El Niño Modoki and its possible teleconnection. J. Geophys. Res., 112, C11007, doi:10.1029/2006JC003798.

Bain, C. L., G. Magnusdottir, P. Smyth, and H. Stern, 2010: Diurnal cycle of the Intertropical Convergence Zone in the east Pacific. J. Geophys. Res., 115, D23116 doi:10.1029/2010JD014835.

Bain, C. L., J. D. Paz, J. Kramer, G. Magnusdottir, P. Smyth, H. Stern, and C. C. Wang, 2011: Detecting the ITCZ in instantaneous satellite data using spatiotemporal statistical modeling: ITCZ climatology in the East Pacific. J. Climate, 24, 216-230.

Boulanger, J. P., and L. L. Fu, 1996: Evidence of boundary reflection of Kelvin and first-mode Rossby waves from TOPEX/POSEIDON sea level data. J. Geophys. Res., 101(C7), 16361-16371, doi:10.1029/96JC01282.

Capotondi, A., M. A. Alexander, and C. Deser, 2003: Why are there Rossby wave maxima in the Pacific at $10^{\circ} \mathrm{S}$ and $13^{\circ} \mathrm{N}$ ?. J. Phys. Oceanogr., 33, 1549-1563.

Dee, D. P., and Coauthors, 2011: The ERA-Interim reanalysis: configuration and performance of the data assimilation system. Q. J. R. Meteorol. Soc., 137, 553-597.

Fu, L. L., and B. Qiu, 2002: Low-frequency variability of the North Pacific Ocean: The roles of boundary- and wind-driven baroclinic Rossby waves. J. Geophys. Res., 107(C12), 3220, doi:10.1029/2001JC001131.

Hasegawa, T., and K. Hanawa, 2003: Heat content variability related to ENSO events in the Pacific. J. Phys. Oceanogr., 33, 407-421.

Hasegawa, T., K. Ando, I. Ueki, K. Mizuno, and S. Hosoda, 2013: Upper-ocean salinity variability in the tropical Pacific: Case study for quasi-decadal shift during the 
2000s using TRITON buoys and Argo floats. J. Climate, 26, 8126-8138.

Horel, J. D., 1982: On the annual cycle of the tropical Pacific atmosphere and ocean. Mon. Weather Rev., 110, 1863-1878.

Kao, H. Y., and J. Y. Yu, 2009: Contrasting eastern-Pacific and central-Pacific types of ENSO. J. Climate, 22, 615-632.

Kaplan, A., Y. Kushnir, M. A. Cane, and M. B. Blumenthal, 1997: Reduced space optimal analysis for historical data sets: 136 years of Atlantic sea surface temperatures. J. Geophys. Res., 102, 27,835-27,860.

Kessler, W. S., 1990: Observations of long Rossby waves in the northern tropical Pacific. J. Geophys. Res., 95, 5183-5217.

Knapp, K. R., and Coauthors, 2011: Globally gridded satellite observations for climate studies. Bull. Amer. Meteor. Soc., 92, 893-907.

Kug, J.-S., F.-F. Jin, and S.-I. An, 2009: Two types of El Niño events: Cold tongue El Niño and warm pool El Niño. J. Climate, 22, 1499-1515.

Larkin, N. K., and D. E. Harrison, 2005: On the definition of El Niño and associated seasonal average U.S. weather anomalies. Geophys. Res. Lett., 32, L13705, doi: 10.1029/2005GL022738.

Levitus, S., 1982: Climatological atlas of the world ocean. NOAA professional paper 13, 173pp. U.S. Government Printing Office, Washington, DC.

Meyers, G., 1979: On the annual Rossby wave in the tropical North Pacific Ocean. $J$. Phys. Oceanogr., 9, 663-674.

Pazan, S., and G. Meyers, 1982: Interannual fluctuations of the tropical Pacific wind field and the Southern Oscillation. Mon. Weather Rev., 110, 587-600.

Philander, S. G., 1989: El Niño, La Niña, and the Southern Oscillation. Academic Press, 
293pp.

Picaut, J., C. Menkes, J. P. Boulanger, and Y. du Penhoat, 1993: Dissipation in a Pacific equatorial long wave model. TOGA Notes, 11-15.

Qiu, B., and S. Chen, 2010: Interannual-to-decadal variability in the bifurcation of the North Equatorial Current off the Philippines. J. Phys. Oceanogr., 40, 2525-2538.

Rayner, N. A., D. E. Parker, E. B. Horton, C. K. Folland, L. V. Alexander, D. P. Rowell, E. C. Kent, and A. Kaplan, 2003: Global analyses of sea surface temperature, sea ice, and night marine air temperature since the late nineteenth century. J. Geophys. Res., 108(D14), 4407, doi:10.1029/2002JD002670.

Schopf, P. S., and M. J. Suarez, 1988: Vacillations in a coupled ocean-atmosphere model. J. Atmos. Sci., 45, 549-566.

Simmons, A. J, K. M. Willett, P. D. Jones, P. W. Thorne, and D. P. Dee, 2010: Lowfrequency variations in surface atmospheric humidity, temperature, and precipitation: Inferences from reanalyses and monthly gridded observational data sets. J. Geophys. Res. 115, D01110, doi:10.1029/2009JD012442.

Singh, A., T. Delcroix, and S. Cravatte, 2011: Contrasting the flavors of El Niño-Southern Oscillation using sea surface salinity observations. J. Geophys. Res., 116, C06016, doi:10.1029/2010JC006862.

Trenberth, K. E., W. G. Large, and J. G. Olson, 1990: The mean annual cycle in global ocean wind stress. J. Phys. Oceanogr., 20, 1742-1760.

Waliser, D. E., and C. Gautier, 1993: A satellite-derived climatology of the ITCZ. $J$. Climate, 6, 2162-2174.

Weisberg, R. H., and C. Wang, 1997: A western Pacific oscillator paradigm for the El Niño-Southern Oscillation. Geophys. Res. Lett., 24, 779-782. 
Xie, S. P., and S. G. H. Philander, 1994: A coupled ocean-atmosphere model of relevance to the ITCZ in the eastern Pacific. Tellus, 46A, 340-350. 


\section{Figure captions}

Figure 1: Climatological annual mean of (a) SST (color; ${ }^{\circ} \mathrm{C}$ ), (b) WSC (color; $\mathrm{N} \mathrm{m}^{-3}$ ) and (c) SSH (color; cm). IR temperature (contours; $2 \mathrm{~K}$ intervals) and wind stress (arrows; $\mathrm{N} \mathrm{m}^{-2}$ ) are superimposed in all of the panels. Black dots denote meridional minima of the IR temperature. Shading conventions and scale of arrows are represented

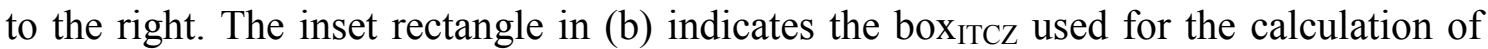
$Y_{I T C Z}(t)$ and $Y_{W S C}(t)$.

Figure 2: Time series of $Y^{\prime}{ }_{I T C Z}(t)$ (solid line; degree in latitude), $Y^{\prime}{ }_{W S C}(t)$ (dashed line; degree in latitude), and the Niño 3.4 index (color; $\left.{ }^{\circ} \mathrm{C}\right)$. Note that the axis for $Y^{\prime}{ }_{\text {ITCZ }}(t)$ and $Y^{\prime}{ }_{W S C}(t)$ is at the left of the panel, but the axis for the Niño 3.4 index is at the right.

Figure 3: Regressed (a) SSTA $\left({ }^{\circ} \mathrm{C} \mathrm{deg}-1\right)$, (b) WSCA $\left(\times 10^{-8} \mathrm{~N} \mathrm{~m}^{-3} \mathrm{deg}^{-1}\right)$, and (c) SSHA (cm deg $\left.{ }^{-1}\right)$ onto the $\left(-Y^{\prime}{ }_{I T C Z}(t)\right)$, superimposed with climatological annual mean of IR temperature at $278 \mathrm{~K}$ (contours). Shading conventions are represented to the right. Black dots in (b) denote locations where the regressed WSCAs explain more than $25 \%$ of the total interannual variance of the WSCAs.

Figure 4: Lead-lag regression maps of the SSHAs onto $\left(-Y^{\prime}{ }_{I T C Z}(t)\right)$. The monthly leadlag value is negative (positive) when the SSHA leads (lags) $\left(-Y^{\prime}{ }_{I T C Z}(t)\right)$. Shading convention is represented at the bottom. The inset boxes indicate the paths for the Hovmöller diagrams in Fig. 5. 
Figure 5: Hovmöller diagrams of the observed SSHAs (color; cm) along (a) an off-equatorial latitudinal belt $\left(9-15^{\circ} \mathrm{N}\right)$ and $(\mathrm{b})$ the equator $\left(3^{\circ} \mathrm{S}-3^{\circ} \mathrm{N}\right)$. Dashed lines in Fig. 5a indicate westward propagations of the waves with a speed of $20 \mathrm{~cm} \mathrm{~s}^{-1}$. Shading convention is represented at the bottom. (c) Time series of $\left(-Y_{\text {ITCZ }}^{\prime}(t)\right)$ (color) and area-averaged WSCA (solid line) over $165-120^{\circ} \mathrm{W}$ and $9-15^{\circ} \mathrm{N}$.

Figure 6: Hovmöller diagrams of the simulated SSHAs (color, $\mathrm{cm}$ ) along the off-equatorial latitudinal belt $\left(9-15^{\circ} \mathrm{N}\right)$ output from (a) the reduced gravity model, (b) the first term and (c) the second term in the model, together with (d) the observed SSHAs along the equator (same as Fig. 5b). Shading convention is represented at the bottom of Fig. 6b. (e) Simultaneous correlation coefficients of the observed off-equatorial SSHAs with the simulated SSHAs (thin solid line), the first term (dashed line) and the second term (thick solid line) as a function of longitude. Also shown are lead-lag correlation coefficients of (f) the second term (Fig. 6c) and (g) the observed equatorial SSHAs (Fig. 6d) with the observed SSHA at $0^{\circ} \mathrm{N}$ and $180^{\circ} \mathrm{W}$ as a function of longitude (contours; 0.05 intervals). The monthly lead-lag value is positive (negative) when the equatorial SSHA at $180^{\circ}$ in the observation leads (lags) the second term and the observed SSHAs. 


\section{Climatologies}
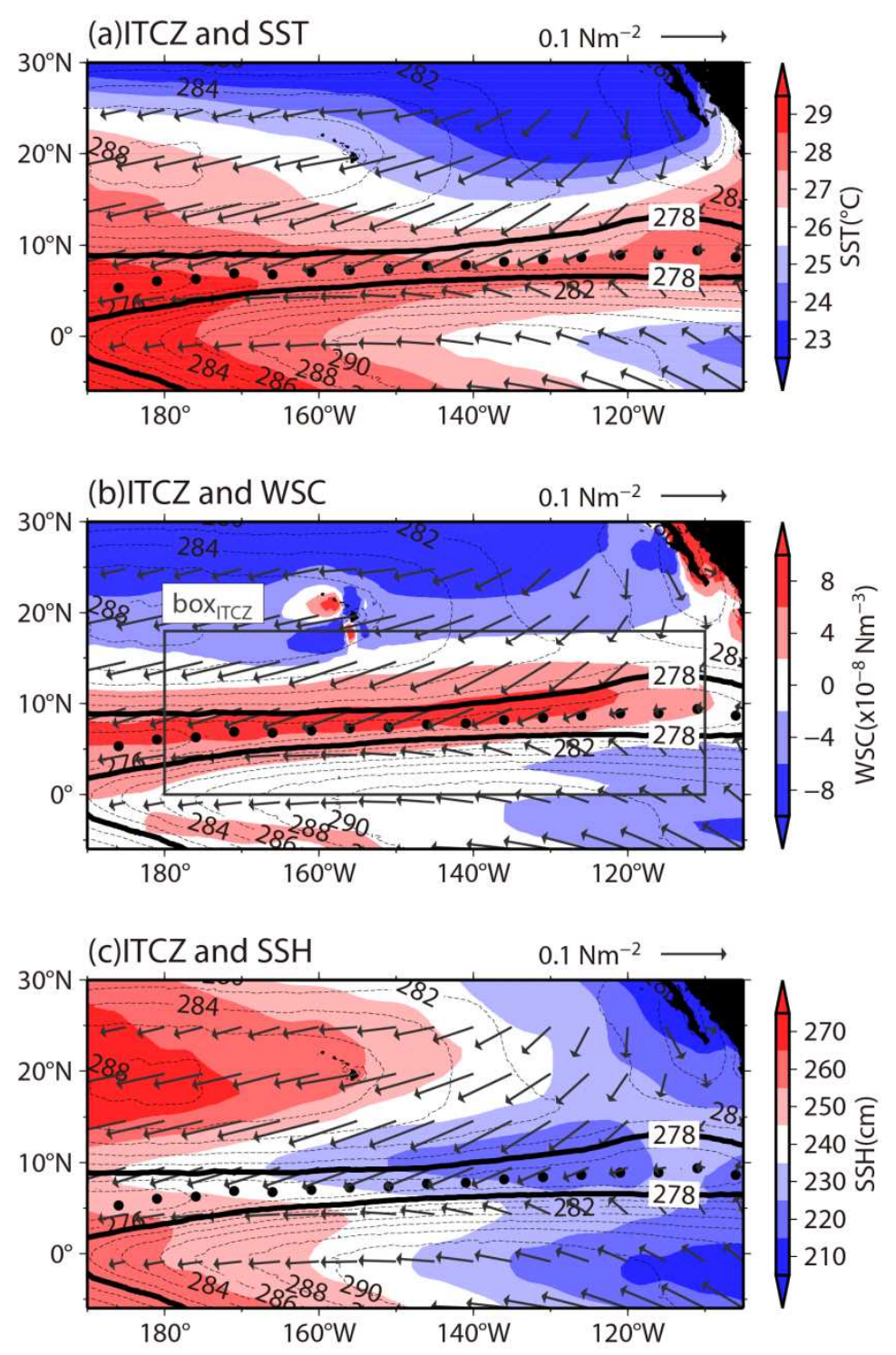

Figure 1: Climatological annual mean of (a) SST (color; ${ }^{\circ} \mathrm{C}$ ), (b) WSC (color; $\mathrm{N} \mathrm{m}^{-3}$ ) and (c) SSH (color; cm). IR temperature (contours; $2 \mathrm{~K}$ intervals) and wind stress (arrows; $\mathrm{N} \mathrm{m}^{-2}$ ) are superimposed in all of the panels. Black dots denote meridional minima of the IR temperature. Shading conventions and scale of arrows are represented

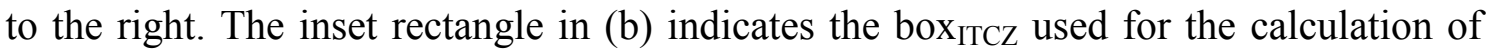
$Y_{I T C Z}(t)$ and $Y_{W S C}(t)$. 


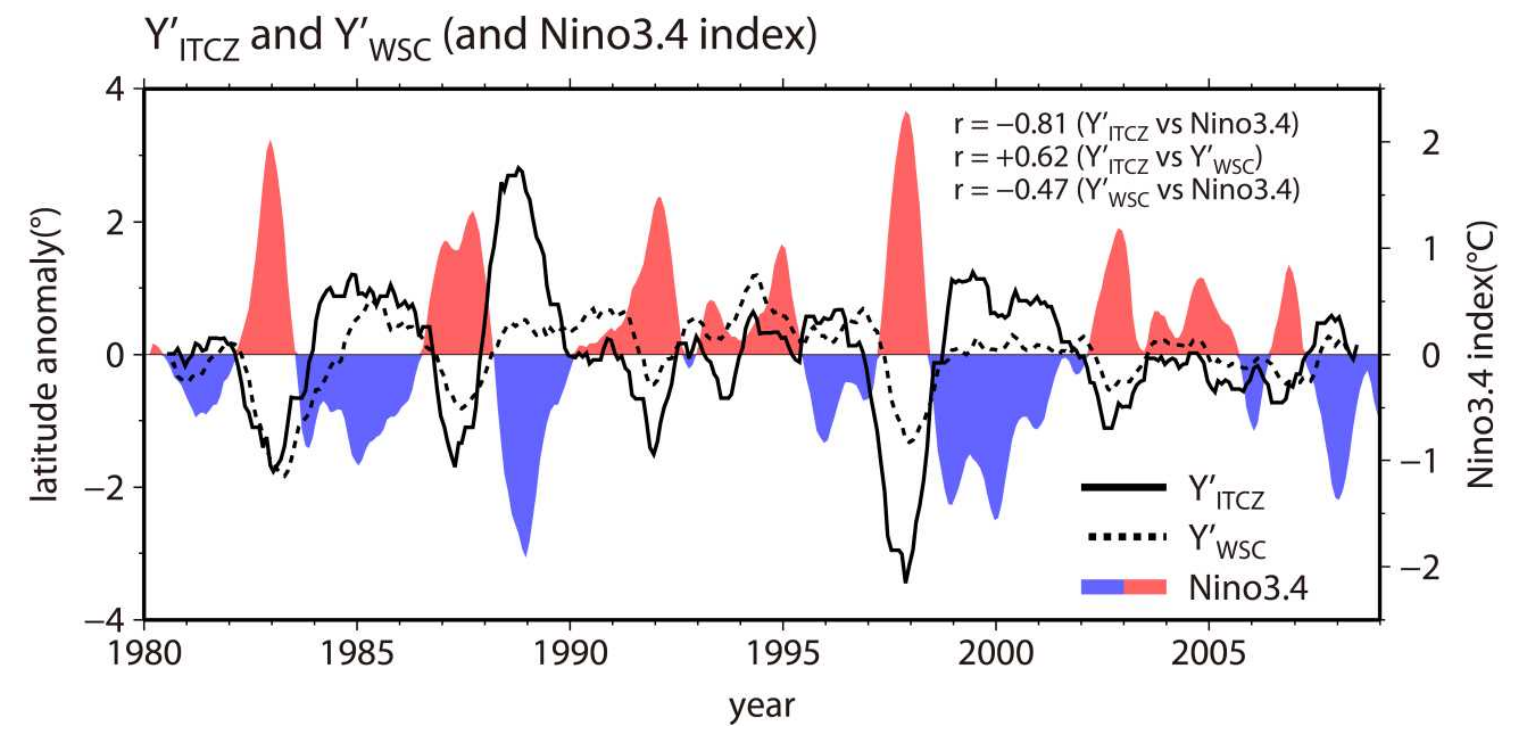

Figure 2: Time series of $Y^{\prime}{ }_{I T C Z}(t)$ (solid line; degree in latitude), $Y_{W S C}{ }_{W S}(t)$ (dashed line; degree in latitude), and the Niño 3.4 index (color; $\left.{ }^{\circ} \mathrm{C}\right)$. Note that the axis for $Y^{\prime}{ }_{\text {ITCZ }}(t)$ and $Y^{\prime}{ }_{W S C}(t)$ is at the left of the panel, but the axis for the Niño 3.4 index is at the right. 


\section{(a)Regressed SSTA}

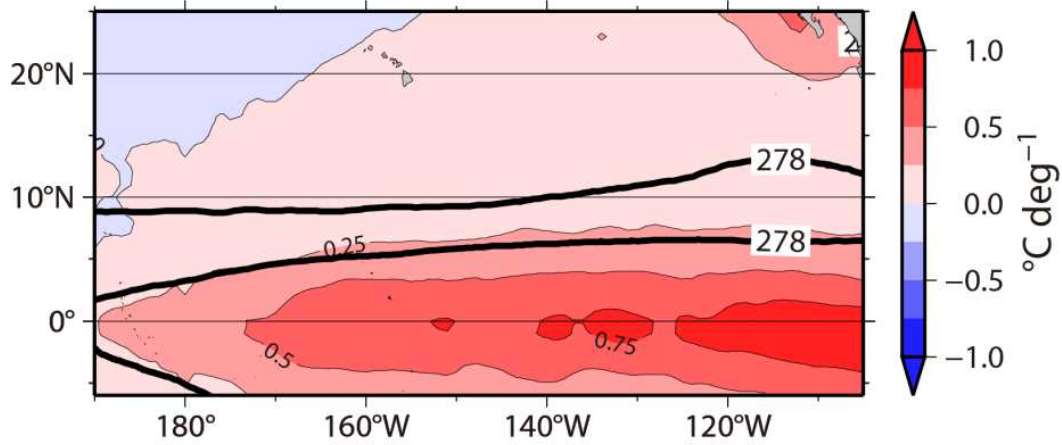

(b)Regressed WSCA

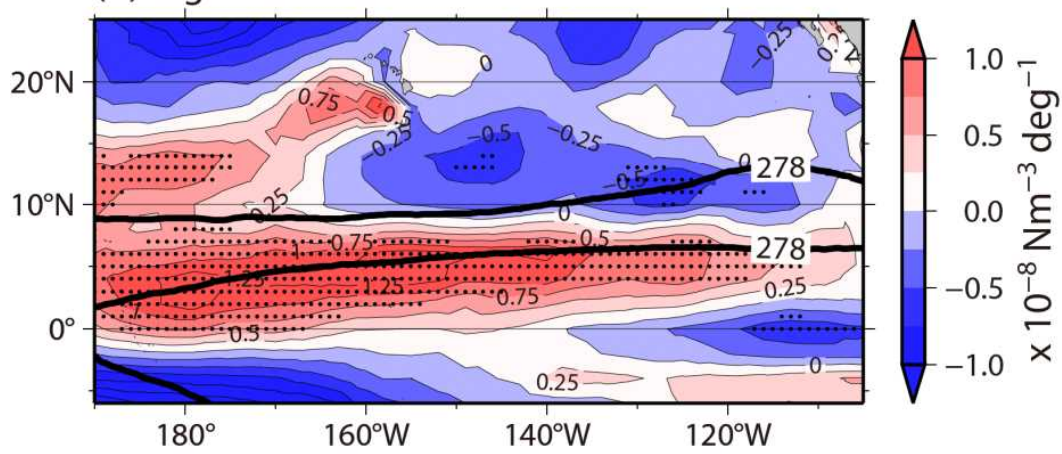

(c) Regressed SSHA

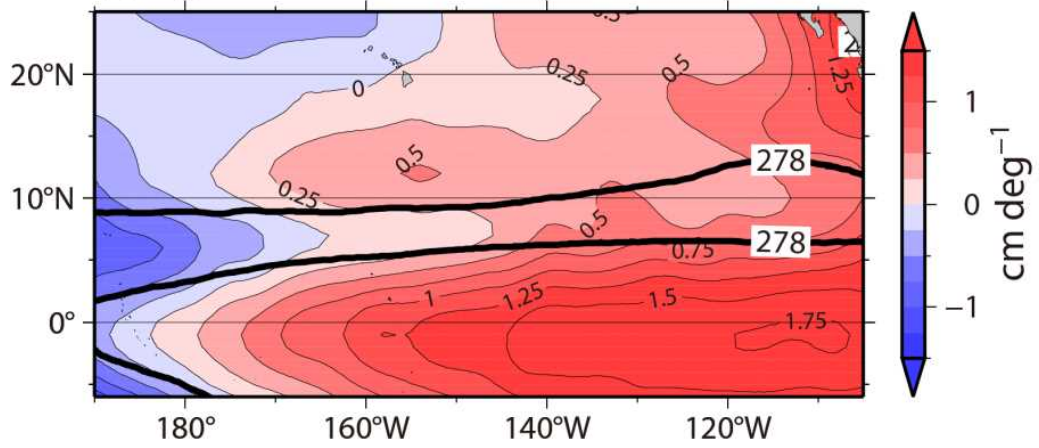

Figure 3: Regressed (a) SSTA $\left({ }^{\circ} \mathrm{C} \mathrm{deg}^{-1}\right)$, (b) WSCA $\left(\times 10^{-8} \mathrm{~N} \mathrm{~m}^{-3} \mathrm{deg}^{-1}\right)$, and (c) SSHA $\left(\mathrm{cm} \mathrm{deg}^{-1}\right)$ onto the $\left(-Y^{\prime}{ }_{\text {ITCZ }}(t)\right)$, superimposed with climatological annual mean of IR temperature at $278 \mathrm{~K}$ (contours). Shading conventions are represented to the right. Black dots in (b) denote locations where the regressed WSCAs explain more than $25 \%$ of the total interannual variance of the WSCAs. 
Regressed SSHA

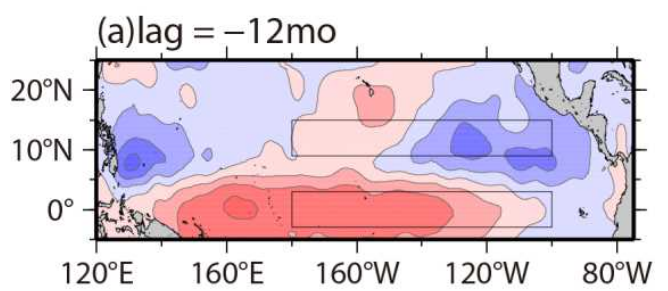

(b) $\operatorname{lag}=-6 \mathrm{mo}$

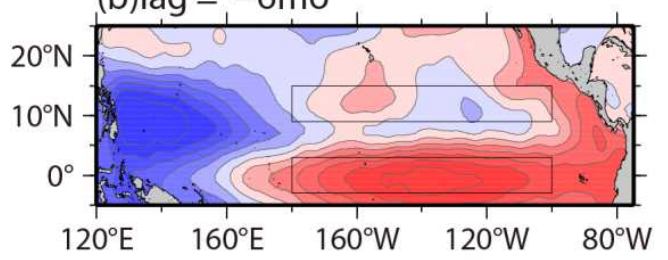

(c) $\operatorname{lag}=0 \mathrm{mo}$

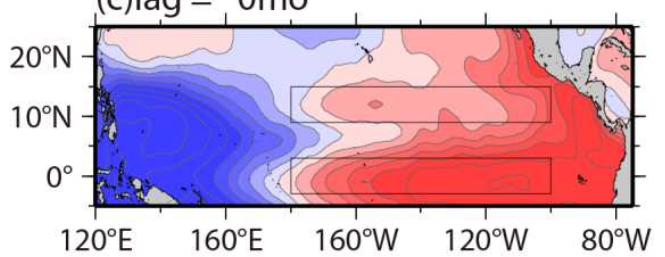

(d) $\operatorname{lag}=+6 \mathrm{mo}$

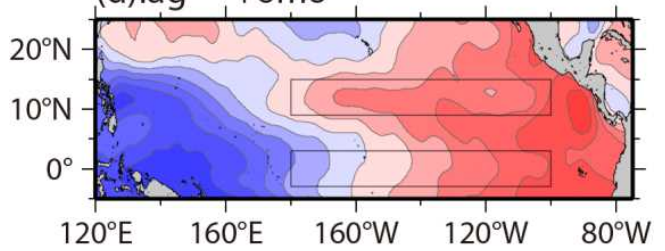

(e) $\operatorname{lag}=+12 \mathrm{mo}$

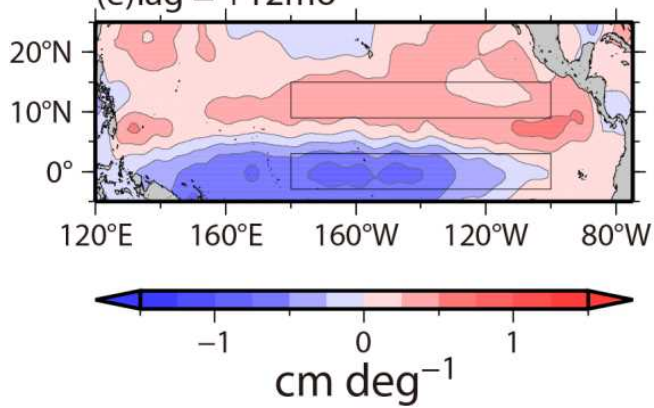

Figure 4: Lead-lag regression maps of the SSHAs onto $\left(-Y^{\prime}{ }_{I T C Z}(t)\right)$. The monthly leadlag value is negative (positive) when the SSHA leads (lags) $\left(-Y_{I T C Z}^{\prime}(t)\right)$. Shading convention is represented at the bottom. The inset boxes indicate the paths for the Hovmöller diagrams in Fig. 5. 


\section{Observed SSHA}

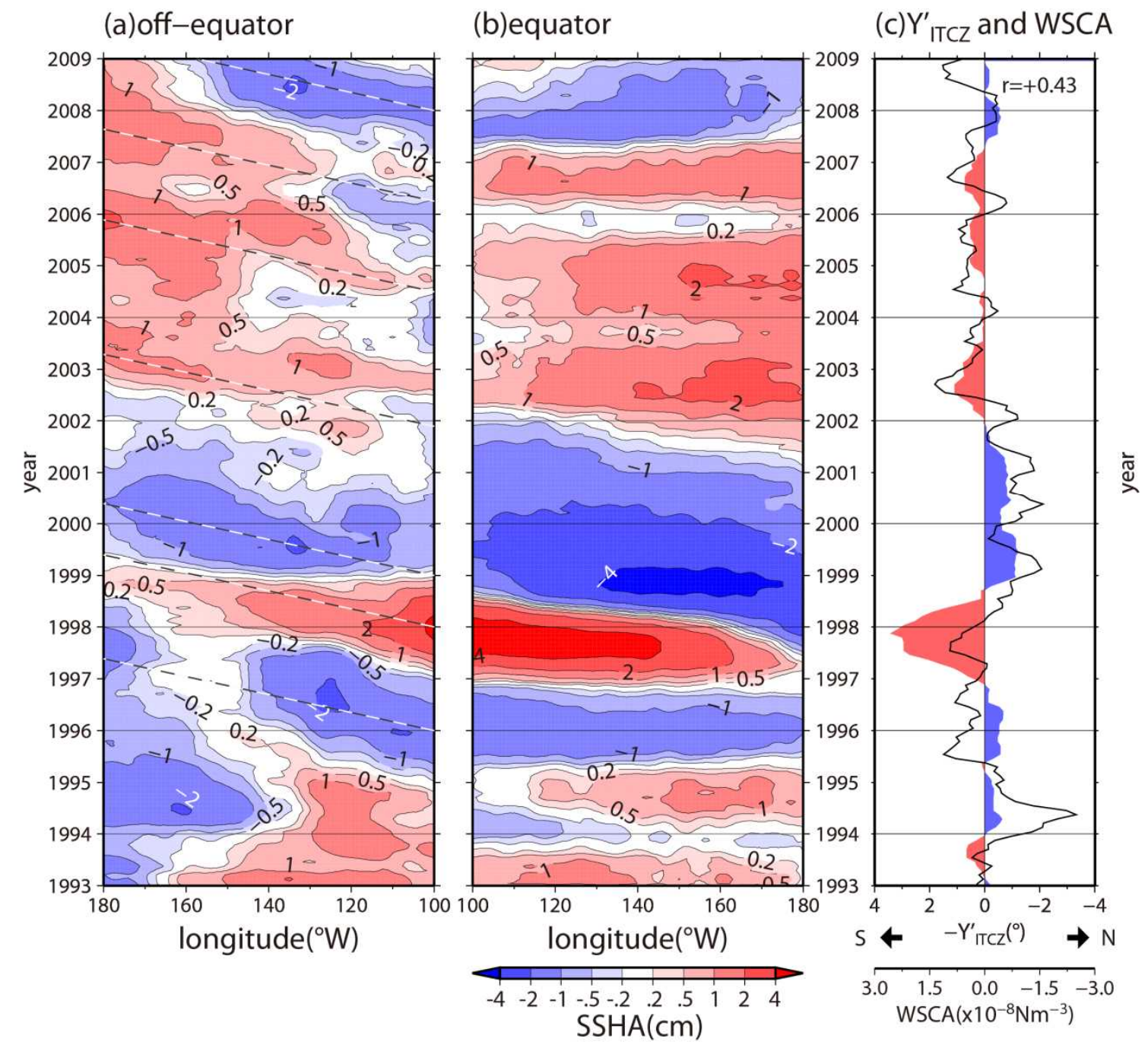

Figure 5: Hovmöller diagrams of the observed SSHAs (color; $\mathrm{cm}$ ) along (a) an off-equatorial latitudinal belt $\left(9-15^{\circ} \mathrm{N}\right)$ and $(\mathrm{b})$ the equator $\left(3^{\circ} \mathrm{S}-3^{\circ} \mathrm{N}\right)$. Dashed lines in Fig. 5a indicate westward propagations of the waves with a speed of $20 \mathrm{~cm} \mathrm{~s}^{-1}$. Shading convention is represented at the bottom. (c) Time series of $\left(-Y_{I T C Z}^{\prime}(t)\right)$ (color) and area-averaged WSCA (solid line) over $165-120^{\circ} \mathrm{W}$ and $9-15^{\circ} \mathrm{N}$. 


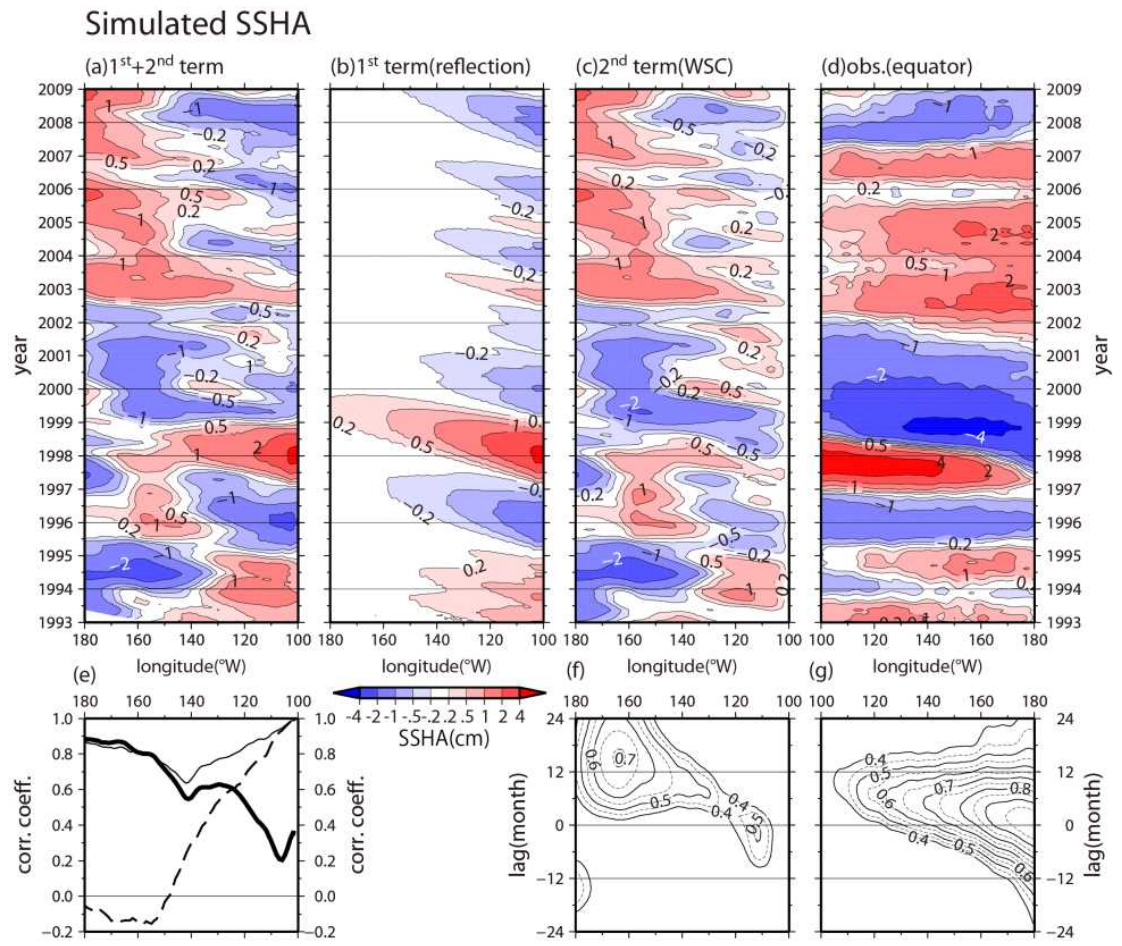

Figure 6: Hovmöller diagrams of the simulated SSHAs (color, $\mathrm{cm}$ ) along the off-equatorial latitudinal belt $\left(9-15^{\circ} \mathrm{N}\right)$ output from (a) the reduced gravity model, (b) the first term and (c) the second term in the model, together with (d) the observed SSHAs along the equator (same as Fig. 5b). Shading convention is represented at the bottom of Fig. 6b. (e) Simultaneous correlation coefficients of the observed off-equatorial SSHAs with the simulated SSHAs (thin solid line), the first term (dashed line) and the second term (thick solid line) as a function of longitude. Also shown are lead-lag correlation coefficients of (f) the second term (Fig. 6c) and (g) the observed equatorial SSHAs (Fig. 6d) with the observed SSHA at $0^{\circ} \mathrm{N}$ and $180^{\circ} \mathrm{W}$ as a function of longitude (contours; 0.05 intervals). The monthly lead-lag value is positive (negative) when the equatorial SSHA at $180^{\circ}$ in the observation leads (lags) the second term and the observed SSHAs. 